Renata Campos Vasconcelos ${ }^{1}$ Francisco de Paula Antunes Lima² Ana Carolina Medeiros da Silveira Abreu $^{3}$

Raquel Christine Ribeiro Silva ${ }^{4}$

João Alberto Camarotto 5

Edmar Pires Murta ${ }^{6}$

\section{A estratégia de "redução" e a carga de trabalho dos co- letores de lixo domiciliar de uma grande cidade: estudo de caso baseado na Análise Ergonômica do Trabalho}

\author{
The "reduction" strategy and the workload of a big city garbage \\ collectors. A case study based on Ergonomic Work Analysis
}

${ }^{1}$ Fisioterapeuta, mestre e doutora em Ergonomia pela Universidade Federal de São Carlos (UFSCar), professora de Ergonomia no curso de Fisioterapia da Pontifícia Universidade Católica de Belo Horizonte (PUC-Minas).

${ }^{2}$ Engenheiro Mecânico, pós-doutor em Ergologia pela Université de Provence, doutor em Ergonomia no CNAM/Paris, professor do Programa de Pós-Graduação em Engenharia de Produção da Universidade Federal de Minas Gerais (UFMG).

${ }^{3}$ Fisioterapeuta pós-graduada em Ergonomia pela Universidade Federal de Minas Gerais (UFMG). Mestranda em Bioética pela Universidad del Museo Social Argentino.

${ }^{4}$ Fisioterapeuta e pós-graduada em Ergonomia pela Universidade Federal de Minas Gerais (UFMG).

${ }^{5}$ Engenheiro Mecânico, doutor em Arquitetura Industrial e pós-doutor em Ergonomia pela Universidade Politécnica de Madrid, professor do Programa de Pós-Graduação em Engenharia de Produção da Universidade Federal de São Carlos (UFSCar).

${ }^{6}$ Psicólogo do Trabalho e mestrando em Psicologia Social na Universidade Federal de Minas Gerais (UFMG).

Contato:

Renata Campos Vasconcelos

Avenida Dom José Gaspar, 500, Prédio 46 - Centro Clínico de Fisioterapia

CEP 30535-901 - Bairro Coração Eucarístico - Belo Horizonte-MG

E-mail:

remineira@yahoo.com.br

Recebido: 05/11/2006

Revisado: 27/05/2008

Aprovado: 29/05/2008

\section{Resumo}

Este trabalho descreve a utilização do método de "redução" como estratégia de trabalho desenvolvida pelos coletores de lixo ("garis") de uma grande cidade e seus reflexos na organização e na carga de trabalho. O método de "redução" consiste de atividade preparatória à coleta de lixo por meio da formação de “estoques intermediários” antes do carregamento nos caminhões. O trabalho dos garis foi estudado utilizando-se a metodologia da Análise Ergonômica do Trabalho (AET), complementada por avaliações de esforço físico. Quanto à organização do trabalho, verificou-se que, ao utilizarem esta estratégia, os garis trabalham em ritmo mais cadenciado, conseguem executar melhor as tarefas de separação do lixo, como os sacos plásticos contendo vidros, podem interagir entre eles e estabelecer relações amistosas com os cidadãos sobre melhores práticas de acondicionamento do lixo. Em relação à segurança e à saúde, ao utilizarem este método, os garis ficam menos sujeitos a riscos de cortes, atropelamentos, quedas e desavenças com motoristas no trânsito, além de realizarem o trabalho com menos esforço físico. Concluiu-se que a utilização da "redução" não apenas diminui o esforço físico e a exposição a riscos de acidentes, mas também melhora a qualidade da coleta de lixo domiciliar.

Palavras-chaves: coletores de lixo domiciliar, método de trabalho, Análise Ergonômica do Trabalho, Organização do Trabalho, carga de trabalho.

\begin{abstract}
This article discusses the "reduction" process as a working strategy implemented by the garbage collectors of a big city and its influence on workload and work organization. The so called "reduction" process consists in preparing garbage bags to be collected piling up 'intermediate stocks' before they are loaded on trucks. Garbage collectors' activitiy was studied through Ergonomic Work Analysis (EWA), supplemented by physiological and biomechanical workload measuring. As far as work organization is concerned, it was observed that when garbage collectors adopt this strategy they improve their work rhythm; they have more possibilities to separate garbage, such as plastic bags containing glass pieces from the rest; they manage to interact more with co-workers and communicate better with local residents on better ways of garbage packing. As regard to health and safety, when garbage collectors follow this process they are less liable to getting cut, to being run over, to falling down or to having quarrels with drivers, and their tasks are performed with less biomechanical load. The authors concluded that the "reduction" strategy not only decreases biomechanical load and exposure to risks, but also improves residential garbage collection.
\end{abstract}

Keywords: garbage collectors, residential garbage, working method, Ergonomic Work Analysis (EWA), work organization, workload. 


\section{Introdução}

Na sociedade pós-industrial, com a utilização crescente de alimentos industrializados e produtos descartáveis, é notória a importância do trabalho dos coletores de lixo para resolver um problema particularmente intenso devido ao consumo massificado das grandes cidades. Chamados de lixeiros, esses profissionais têm sua carteira assinada com a função de "garis". A relevância desta categoria no quadro urbano contemporâneo nem sempre tem sido correspondida com análises do trabalho em geral ou estudos que se situem na perspectiva da saúde dos coletores de lixo.

Conforme a NR-15 da portaria 3214 do Ministério do Trabalho de 03/06/1978, o trabalho de coleta de lixo domiciliar é considerado insalubre em grau máximo (SANTOS, 2004; ROBAZZI et al., 1992). Em alguns estudos, constatam-se diversos tipos de patologias relacionadas ao trabalho dos garis, tais como doenças respiratórias e cardiovasculares, distúrbios osteomusculares, perdas auditivas, dentre outras (SILVA, 1983; ROBAZZI; BECHELLI, 1985; ROBAZZI et al., 1992; MADRUGA, 2002; PAVELSKI, 2004).

A carga de trabalho dos garis aumenta com o crescimento populacional das cidades e esses profissionais precisam responder a diferentes objetivos: da empresa, da comunidade, bem como os pessoais, ou seja, dos próprios trabalhadores. Para atingir tais objetivos, os trabalhadores precisam lidar com diferentes exigências de tempo, qualidade e segurança, desenvolvendo estratégias e regulações a fim de manter sua carga de trabalho aceitável.

A demanda para a pesquisa, objeto deste artigo, surgiu da necessidade de compreensão de um "método de trabalho" utilizado pelos garis de uma grande cidade brasileira, chamado por eles de "redução" . Este "método de trabalho" ou "modo de organização da produção", desenvolvido pelo próprio grupo de trabalhadores, consiste de atividade preparatória à coleta de lixo por meio da formação de "estoques intermediários" que permitem reduzir os pontos de parada dos caminhões para coleta do lixo, além de propiciar outros benefícios para a regulação da carga de trabalho pela equipe.

No entanto, embora seja realidade das atividades cotidianas da coleta, a "redução" não é reconhecida como procedimento de trabalho pela empresa (exceto em algumas situações). Na situação estudada, a "redução" é percebida na empresa como estratégia para burlar as normas de trabalho, ou seja, uma indisciplina passível de sanção pela hierarquia. Para a empresa, ela é prejudicial à qualidade de limpeza urbana, por gerar transtornos aos próprios trabalhadores e para a população, que se queixa do acúmulo de lixo em frente às suas casas. Para os garis, a "redução" diminui a carga de trabalho e evita acidentes.

Compreender a "redução", seus efeitos para a saúde dos garis e para a qualidade dos serviços prestados surge como problema a ser analisado sob a perspectiva da Análise Ergonômica do Trabalho (AET) (GUERIN et al., 2001), que nos ajuda a entender porque existem diferentes representações em torno de uma mesma realidade.

Conforme explica Abrahão (1993), a Ergonomia procura evidenciar os componentes físico, psíquico e cognitivo da atividade de trabalho, seus diferentes determinantes, o custo para realizá-la, isto é, a "carga de trabalho" e sua repercussão sobre a saúde dos trabalhadores e sobre a produção. Enquanto a dimensão física da carga de trabalho se expressa pela quantidade e qualidade de esforço físico despendido pelo trabalhador na execução da atividade, a dimensão cognitiva caracteriza-se pelas funções perceptivas e mentais exigidas para a realização do trabalho, sendo que o conteúdo cognitivo de uma tarefa reflete na tomada de decisão. A dimensão psíquica, considerada a mais difícil de qualificar e quantificar, relaciona-se com o grau de realização existencial ou sofrimento psíquico do trabalhador e reflete os componentes psicológicos, tais como desejo, angústia, afetividade, medo, presentes no trabalho ou conseqüentes dele.

Sabe-se que existe relação entre carga de trabalho e desenvolvimento de modos operatórios ou métodos de trabalho (GUÉRIN et al., 2001). A carga de trabalho é máxima quando os operadores só dispõem de um modo operatório possível, ou seja, quando dispõem de pouca margem de ação. O objetivo da AET é, assim, aumentar a margem de ação dos operadores, possibilitando outras formas de agir e criando melhores condições de trabalho.

Para demonstrar a validade da "redução" para a preservação dos agravos, são descritos, neste artigo, os critérios de sua execução, a percepção dos trabalhadores sobre ela e sobre sua carga de trabalho, assim como são apresentados os resultados de medidas fisiológicas tomadas para comparar o esforço físico dos trabalhadores quando a "redução" é colocada em prática ou não.

\section{Métodos e técnicas}

Para compreender a atividade dos garis, a pesquisa baseou-se na metodologia da Análise Ergonômica do Trabalho (AET).

A AET fundamenta-se no referencial teórico da Ergonomia da Atividade e visa confrontar o traba-

${ }^{7}$ O termo "redução" é utilizado no texto entre aspas, pois, como os trabalhadores utilizam o verbo "reduzir", acabamos por incorporá-lo ao texto. 
lho prescrito aos trabalhadores e as condições de sua execução com o trabalho realmente desenvolvido por eles. Esta metodologia:

[...] é um meio de revelar novas questões sobre o funcionamento do homem no trabalho, mas também uma abordagem original para a transformação e a concepção dos meios técnicos e organizacionais de trabalho. (GUÉRIN et al., 2001, p. 26)

Segundo Guérin et al. (2001), uma ação é ergonômica quando comporta uma análise da atividade de trabalho que contribui para demonstrar as estratégias usadas pelos trabalhadores para executar suas tarefas e, assim, atingir os objetivos traçados pelos representantes da empresa, mas que são, de certa forma, desconhecidas. Este tipo de análise permite compreender os elementos intrínsecos e extrínsecos que afetam direta ou indiretamente os trabalhadores, demonstrando-se, de forma concreta, como esses fatores se manifestam no cotidiano e na execução de suas atividades de trabalho.

Nesta pesquisa, foram aplicadas as seguintes técnicas: observação da atividade dos trabalhadores, filmagens, fotografias, verbalizações simultâneas, autoconfrontações individuais e coletivas, entrevistas coletivas e não estruturadas com diferentes atores da empresa (GUÉRIN et al., 2001; WISNER, 2004; VASCONCELOS, 2007).

Para avaliar o esforço físico, foram tomadas medidas de freqüência cardíaca (FC) e pressão arterial (PA) durante o trabalho feito com e sem "redução".

A mensuração da FC representa um controle fisiológico difundido para se avaliar a intensidade do esforço a que o organismo está sendo submetido, refletindo a intensidade de trabalho que o coração deve realizar para satisfazer as demandas aumentadas do corpo durante uma atividade. Para isso, deve-se comparar a FC de repouso (FCrep) com a FC durante o exercício. Em média, a FCrep é de 60 a 80 batimentos/minuto e tipicamente diminui com a idade (ROBERGS; ROBERTS, 2002; WILMORE; COSTILL, 2001).

Quando se começa a exercitar, a taxa de bombeamento de sangue aumenta e o sangue possui menos tempo para preencher as câmaras cardíacas e para ser ejetado do coração. Contudo, a função cardíaca melhora com aumentos da FC induzidos pelo exercício. Então, mais sangue é recebido e bombeado a cada batimento durante o exercício progressivo. Nesses termos, a FC aumenta em proporção direta ao aumento da intensidade do exercício até se encontrar próxima do ponto de exaustão. À medida que isso acontece, a FC começa a se estabilizar, indicando que está se aproximando do valor máximo. A Freqüência Cardíaca Máxima (FCmáx) tende a ser estável e é o valor mais elevado da FC que se pode atingir num esforço máximo até o ponto de exaustão. Embora a FC aumente proporcionalmente com os aumentos na intensidade do exercício, outros fatores também alteram a resposta da FC ao exercício, tais como a duração do exercí- cio, a hidratação, a temperatura corporal, a altitude, a poluição do ar, o excesso de treinamento e doenças (MCARDLE; KATCH; KATCH, 1998; ROBERGS; ROBERTS, 2002; WILMORE; COSTILL, 2001).

A FCmáx, que foi calculada a partir da fórmula 220 menos a idade (220 - id), teve por objetivo conhecer a FC máxima esperada para a idade de cada indivíduo. Além da FCmáx, verificou-se, também, a Freqüência Cardíaca Sub-máxima (65\% a 80\% da FCmáx), pois o treinamento contínuo de natureza sub-máxima a partir de 30 minutos diários é um dos meios mais antigos para se desenvolver resistência aeróbica (MCARDLE et al., 1998).

Para avaliar os dados cronotrópicos - Freqüência Cardíaca (FC) e Pressão Arterial (PA) - foram utilizados um estetoscópio e um esfigmomanômetro, ambos da marca BD, e um freqüencímetro de pulso, da marca POLAR BEATPRT161312E. Os aparelhos foram calibrados e cedidos pelo Laboratório de Pesquisa do Ambulatório de Fisioterapia da PUC Minas-BH. A mensuração da PA ocorreu no início e ao final da jornada e 15 minutos após o término do trabalho. Já a mensuração da FC ocorreu no início da jornada de trabalho, de 10 em 10 minutos durante todo o trabalho, no fim da jornada e 15 minutos após a parada.

A aferição da freqüência cardíaca (FC) pelo sistema polar permitiu uma leitura imediata da FC durante o exercício por ser precisa e não alterar a rotina de trabalho dos garis. Para entendimento do texto, é preciso esclarecer que o Gari 1, apesar de não ter feito "redução", coletou o lixo deixado em montes pelo Gari 2, que fez a "redução" num dia. Também é importante esclarecer que ambos fizeram a coleta sem "redução" e que a comparação dos dados foi intrapessoal, ou seja, o Gari 1 foi comparado com ele mesmo coletando os montes da "redução" e coletando de porta em porta. O mesmo foi feito com o Gari 2, fazendo "redução" e coletando de porta em porta. Tais dados foram coletados durante duas jornadas de trabalho de um mesmo dia da semana: em um dia não foi feita "redução" e, no mesmo dia da outra semana, os garis trabalharam normalmente, isto é, com "redução".

As observações, as entrevistas e as medidas foram feitas apenas com o consentimento dos operadores que assinaram um Termo de Consentimento Livre e Esclarecido, conforme modelo elaborado pelo Laboratório do Grupo de Pesquisa e Extensão em Ergonomia e Projeto do Trabalho.

\section{Resultados e discussão}

\section{Situação estudada}

A empresa estudada, uma autarquia municipal, tem atualmente 1.900 funcionários, sendo 906 garis, dos quais 300 realizam a coleta domiciliar de algumas 
regionais. De acordo com o relatório de atividades da empresa referente a março de 2004, havia 319 garis efetivados e 616 garis de empresas terceirizadas, o que representava quase $70 \%$ do contingente total de trabalhadores (SANTOS, 2004). Em 1992, o quadro total de funcionários era de aproximadamente 5.000, o que demonstra a crescente terceirização dos serviços. Há sete anos a empresa não contrata novos garis. Como a empresa implementou um grande processo de terceirização, os garis foram se aposentando e os remanescentes foram remanejados como garis reserva das poucas regionais efetivadas que ainda restaram.

Além de confundir os funcionários da própria empresa com relação à estrutura organizacional e às funções específicas de cada parte, para $\operatorname{Santos}^{8}$ (2004), essa reforma administrativa enfraqueceu sua dimensão técnica e fortaleceu sua dimensão política. A partir do ano 2000, houve uma aceleração do processo de terceirização dos serviços, com conseqüente diminuição de investimentos em manutenção e compra de equipamentos (SANTOS, 2004), que estão em mau estado de conservação, problema visível para quem acompanha o trabalho de coleta de lixo domiciliar ${ }^{9}$.

Para dar conta da administração, bem como da limpeza urbana, a cidade é dividida em nove regionais. A cidade, que foi projetada no início do século para ter no máximo 200 mil habitantes, atingiu um total de 208 mil habitantes já no ano de 1938 (SANTOS, 2004). A crescente industrialização, a partir da década de 1940, contribuiu ainda mais para o aumento populacional do município, que, em 2001, possuía 2.400.000 habitantes.

\section{O trabalho prescrito}

Cabe aos garis coletar o lixo de porta em porta, arremessando os sacos no caminhão. Na Figura 1, o ciclo básico do trabalho de coleta pode ser observado.

O setor de planejamento de coleta da empresa prescreve o modo ideal de realização desta atividade, que deve ser executada por uma equipe completa, isto é, quatro garis e um motorista. A coleta deve ser realizada de porta em porta, onde cada munícipe deve depositar o lixo acondicionado em sacos plásticos para ser recolhido pelos garis.

Conforme a prescrição, o gari deve se deslocar acompanhando o movimento do caminhão durante todo o roteiro. A permanência sobre o estribo só deve ocorrer quando o caminhão fizer deslocamentos maiores dentro do próprio roteiro, previamente definido, ou no caminho entre a empresa e o ponto de coleta. Também é responsabilidade do gari fazer a “prensagem do lixo”, isto é, compactar o lixo que está no cocho para dentro do baú.

A letra V simboliza momentos em que o gari pára e separa o lixo reciclável, ou faz a compactação do lixo, ou realiza pausas.

Em determinadas situações, os garis também separam o lixo reciclável, deixando-o por certo tempo sobre o estribo. Eles também realizam pausas para ingerir líquidos ou para tomar lanches e aproveitar para conversar com moradores. Estas atividades estão representadas pela Figura 1 como letra V, que representa as variações no ciclo de trabalho prescrito.

Como dito anteriormente, o método de "redução", atividade preparatória à coleta de lixo por meio da formação de "estoques intermediários", que permitem reduzir os pontos de parada dos caminhões para coleta do lixo, não é recomendado formalmente pela empresa como prática corrente. No entanto, em dadas situações, um tipo de "redução" formal pode ser preconizado pela empresa.

Essa "redução" formal é prevista para situações em locais inacessíveis ao caminhão. Nestes casos, o motorista deve parar em local mais próximo e aguardar os garis trazerem o lixo nas mãos, o que causa insatisfação por parte dos garis, que relatam ter de caminhar mais de 200 metros com vários sacos de lixo nas mãos e, portanto, sempre reclamam da "redução oficial". Esta é uma das razões pelas quais os gerentes e engenheiros não aceitam que a prática da "redução espontânea” possa ser benéfica aos garis.

A análise detalhada dos modos operatórios e das estratégias dos garis, quando decidem como, onde e quando fazer a "redução", mostrará como esta contradição será resolvida.

\section{A coleta de lixo baseada no método de "redução": o trabalho real}

Para lidar com a variabilidade da coleta de lixo domiciliar e para regular a carga de trabalho, os garis criaram, dentre várias outras estratégias, a estratégia de "redução". Nos dias em que há menor quantidade de lixo, o trecho é subdividido em uma, duas ou três viagens, conforme a quantidade de lixo a ser coletado. Quando o baú do caminhão fica lotado de lixo, o motorista vai ao aterro sanitário descarregá-lo. Enquanto isso, dois garis descansam e os outros dois realizam a "redução": dividem-se e saem a pé, coletando o lixo de porta em porta, criando montes de lixo em lugares específicos de cada quarteirão até "reduzirem" em todo o trecho restante. Assim, o gari deixa o saco de lixo

\footnotetext{
${ }^{8}$ Psicólogo do trabalho da empresa.

${ }^{9} \mathrm{O}$ que repercute no trabalho dos garis. Por exemplo, as quebras freqüentes dos caminhões em função de seu desgaste e tempo de uso determinam a prática da "redução" por parte dos garis, caso contrário teriam de ficar parados esperando os motoristas voltarem da manutenção.
} 


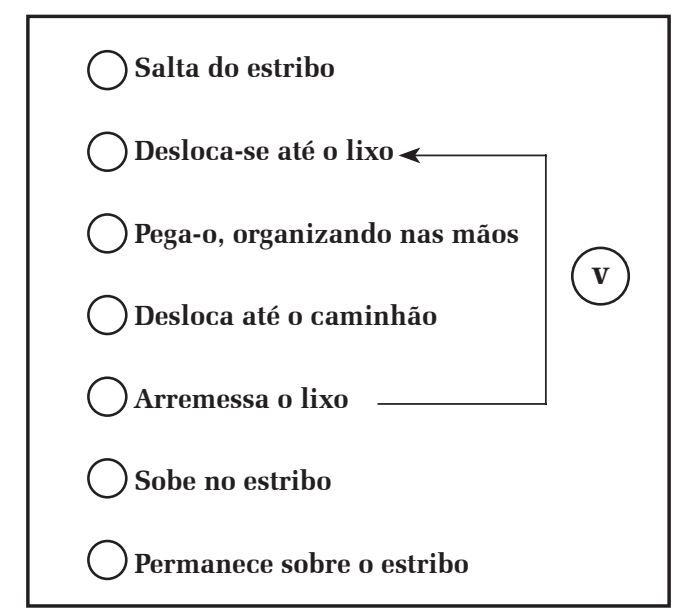

Figura 1 Fluxograma do trabalho prescrito

que contém vidro quebrado ou outro elemento perigoso mais distante do monte de lixo para o gari que vai arremessá-lo, mais tarde, para dentro do cocho do caminhão.

Quando o motorista retorna do aterro sanitário, encontra os outros dois garis que o aguardavam para coletar o lixo "reduzido". O caminhão percorre o restante do trecho com os dois garis que coletam o lixo desses montes. Ao final do trecho, encontram os garis que "reduziram". Quando os garis que "reduzem" terminam antes, reencontram os colegas em alguma parte do trecho para terminarem a coleta com a equipe completa. Outros voltam para a sua regional ou aguardam os colegas no fim do trecho. Os garis costumam voltar de carona em outro caminhão ou carro da empresa que vai para a regional ou pedem carona para os motoristas de ônibus. Outros voltam a pé, dependendo da distância entre o local de coleta e sua regional.

O lixo não fica acomodado apenas em sacos plásticos. É comum encontrar pedaços de madeira, objetos fora das sacolas deixados por pedestres, sacos de poda e folhas de jardins, sacos de entulho e até móveis velhos. Além disso, o tipo e o peso dos sacos varia bastante, de forma que eles precisam encontrar diferentes formas de acondicionar o lixo dentro do cocho do caminhão, sempre tomando cuidado para não serem feridos por vidros quebrados. Às vezes empurram o lixo para perto do cocho e depois carregam os sacos em duplas. Quando o lixo está solto, usam pedaços de madeira como ferramenta para limpar o chão.

Apesar de algumas equipes não fazerem "redução" às segundas e terças-feiras por considerarem que o lixo já está reduzido devido à grande quantidade nas portas de casas e prédios, há equipes que reduzem também nesses dias. Esta decisão depende também do trecho em que os garis se encontram, se ali há mais ou menos lixo, se o lixo está mais ou menos concentrado em alguns pontos, principalmente no caso de edifícios de apartamentos. As equipes que não reduzem o lixo nesses dias explicam por quê:
É certo que dia de segunda e terça não tem jeito de reduzir.

Porque a massa de lixo aumenta, né! Aí tem tanto lixo que já tá reduzido naturalmente... Não seria viável... tenho que dá umas cinco braçadas.

Se você reduzir, vai ciente que vai cansar mais.

Segunda e terça fica na mesma.

... Não vai ser todo dia... se na segunda eu vou gastar 3 horas pra reduzir o trecho, na quarta e na sexta vou gastar 40 minutos.

Entretanto, há equipes que fazem a "redução" inclusive nos dias mais pesados. Há um trecho em que uma equipe reduz num momento diferente: em algumas avenidas, enquanto o caminhão segue a avenida, dois garis se separam da equipe e reduzem na contramão. Assim, quando o caminhão retorna ao fim da avenida e passa para o outro lado da mesma avenida, o lixo já está reduzido. Então, a dupla que ficou no caminhão apenas coleta o lixo dos montes, até que o caminhão encontre a dupla que estava fazendo "redução" para continuarem a coleta com a equipe completa.

Não há um local pré-determinado no trecho para o início da "redução". Num dos casos, quando o baú do caminhão está cheio, o motorista vai ao aterro e inicia-se a "redução". Desta forma, o início da "redução" dependerá da quantidade de lixo no dia. Caso o caminhão quebre (um fato comum), os garis começam a reduzir a partir dali, mesmo na primeira viagem, caso não retornem para a garagem da empresa.

Uma variação desta estratégia é chamada de "inversão de trecho": um gari, na carona com outra equipe, dirige-se ao local de coleta antes do horário de sua equipe iniciar o trabalho e inicia sozinho a "redução". Os colegas o encontram mais à frente do trecho, enquanto vão coletando o lixo já reduzido.

Em situações em que os moradores se atrasam para colocar o lixo para fora de casa, há momentos em que os garis também fazem "redução". Por exemplo, em dada situação, após a passagem do caminhão, uma senhora chamou o gari, que rapidamente avisou 
os colegas para seguirem, separou-se da equipe, desceu a rua e coletou os sacos de lixo daquela casa. Ao invés de correr atrás do caminhão, cortou caminho e desceu fazendo "redução" até reencontrar o caminhão uns três quarteirões à frente.

\section{Regras para se fazer a "redução"}

As equipes definiram algumas regras para a realização da "redução" que permitem administrar os possíveis conflitos com a população:

- gari reserva (aquele que substitui um colega ausente) não pode reduzir por não conhecer os locais apropriados para fazer os montes, a não ser que ele já conheça o roteiro;

- os garis não podem reduzir no meio da calçada, embaixo de janelas, em frente a garagens, muito próximo a estabelecimentos comerciais;

- não podem reduzir em esquinas para não atrapalhar o trânsito ${ }^{10}$;

- se houver queixa da população, é preciso encontrar outro local para os montes, geralmente negociado pelos garis com os próprios moradores.

As regras nem sempre são obedecidas, já que nas filmagens pôde-se ver, por exemplo, lixo reduzido na porta de algumas casas de esquina, inclusive sobre a calçada. Entretanto, como foi dito, os garis costumam negociar com a população. Caso o munícipe reclame para eles ou para a empresa quanto ao local utilizado para acumulação do lixo, os garis transferem o ponto dos montes de lixo para outro local.

Outra exceção é possível: a colocação do monte de lixo no lado esquerdo da rua. O monte de lixo é feito, normalmente, do lado direito da rua para que a coleta seja segura, ou seja, os garis chegam com o caminhão e não precisam atravessar a rua. De acordo com os garis, o monte só é feito do lado esquerdo quando não é possível colocar o lixo do lado direito da rua ou no caso de já haver uma grande quantidade de lixo do lado esquerdo. Neste caso, eles aproveitam o monte existente levando mais lixo para aquele local. Caso a rua não seja movimentada, o motorista costuma parar o caminhão na contramão enquanto os garis coletam, mesmo que ela seja de mão dupla.

Como a "redução" é feita do lado direito da rua, os garis que coletam o lixo reduzido se deslocam para o lado direito do estribo antes de descerem do caminhão. Quando o lixo precisa ser reduzido na contramão, o motorista pára o caminhão na contramão também, próximo ao monte. Se a rua for movimentada, o motorista faz retorno para encostar-se no sentido de deslocamento.

Nos dias em que há menos lixo, geralmente de quarta-feira a sábado, só se realiza a coleta em uma ou duas viagens. Quando uma viagem basta, não há "redução" nem é preciso aguardar o motorista ir e voltar do aterro sanitário, a não ser que o caminhão quebre ou que um gari "reduza” desde o início do trecho, como descrito acima.

\section{Benefícios do uso da "redução"}

Embora o uso da "redução" por parte dos garis faça parte da sua realidade de trabalho, para os representantes da empresa, ela é difícil de ser aceita devido às queixas dos munícipes e à sua interferência nas campanhas sobre os horários de coleta e na crença de que a "redução" cause aumento da carga de trabalho para os garis. Segundo um de seus representantes:

Ao reduzir, o gari tem um dispêndio maior de energia, pois o movimento de correr (no caso da coleta porta-a-porta) o impulsiona, diminuindo o esforço no momento de jogar o lixo no caminhão.

Com relação à posição da população a respeito do uso da "redução", a pesquisa feita pelo setor de Psicologia do Trabalho da empresa mostra que boa parte da população não é contrária a esta prática. Foram realizadas entrevistas dirigidas com 1.398 moradores da região leste da cidade, nos distritos de coleta atendidos pelos garis da empresa. Buscou-se saber a percepção da comunidade sobre a coleta domiciliar e a aceitação da "redução" como modo operatório para realização da atividade, passando pelas residências das ruas em que a "redução" era feita. Do total, 13\% dos entrevistados mostraram-se desfavoráveis à "redução" em frente a suas casas, devido ao mau cheiro e à sujeira. Não houve reincidência de queixas dos moradores que já haviam se queixado à empresa. Este fato decorre, provavelmente, da habilidade do gari em se relacionar com a população, o que lhe permite, inclusive, conhecer os locais onde não há condições de negociação.

A segurança do trabalho não vê impedimento para a realização da "redução" porque esta prática diminui o risco de acidentes e o tempo ocioso nos intervalos das viagens, o que, muitas vezes, poderia facilitar a ingestão de bebidas alcoólicas (estudo sobre "redução" cedido pela empresa, fev/2004).

Sob o ponto de vista dos garis, a "redução" traz diversas vantagens que variam segundo vários aspectos. Tentaremos subdividir abaixo apenas para fins didáticos.

Entretanto, é preciso lembrar que a carga de trabalho contém aspectos mentais e físicos, cuja separação é difícil de estabelecer. Um exemplo dessa impossibilidade está no relato abaixo, em que o gari demonstra o por que prefere usar a estratégia de "redução":

${ }^{10}$ Conforme afirma um gari: "na esquina não pode porque fecha o trânsito". 
Trabalho com "redução" é melhor porque evita acidente no trabalho, reduz a necessidade de correr, é melhor pro corpo e pra mente, evita corte, evita cair.

Quando usada pelos garis durante a jornada de trabalho, a "redução" permite separar as tarefas de coletar e carregar o caminhão, diminuindo-se, desta forma, os riscos de acidentes. Quando ela não ocorre, os garis precisam atravessar a rua observando a passagem dos veículos para não serem atropelados (e zelar pela segurança dos colegas), olhar para os locais onde está o lixo, pegá-lo, observar no retorno para a via onde está o caminhão, arremessar o lixo sem atingir o colega e perceber a arrancada do caminhão.

Se você bate o "reduzido" praticamente você vai efetuar uma ação só. Quer dizer, o caminhão parou e você vai jogar o lixo pra dentro. O motorista vai tá olhando o trânsito, vai tá sinalizando. O lixo sem a "redução" não.

No caso de coleta sem "redução":

... Compete a quem? Ao grupo todo. Tanto o motorista quanto os garis vão ter que fazer... o quê? O caminhão vai andando e o coletor vai ter que pular, vai ter que olhar o trânsito, vai ter que olhar o lixo, vai ter que tá olhando o caminhão correr. Aí que eu acho que o desgaste é bem maior, tanto mentalmente, quanto físico.

A reorganização do trabalho, propiciada pela aplicação da "redução", é vista como positiva pelos garis, além de melhorar a qualidade da coleta, pois não ocorrem quedas de lixo nas ruas, que acontecem quando os garis precisam arremessar os sacos com o caminhão em movimento e com o trânsito de carros.

Comparado com o trabalho prescrito, o trabalho feito com a "redução" oferece vantagens em relação à segurança, possibilita mais relações sociais com a comunidade, assegura o estabelecimento de regulações da carga de trabalho e exige menor esforço físico dos trabalhadores.

\section{Segurança, prevenção de acidentes e carga de trabalho}

Ao realizar a “redução”, o gari tem condições de separar o lixo perigoso, que contém vidro quebrado ou outros elementos perfurocortantes, deixando os sacos mais distantes do monte principal. O coletor sabe que aquele saco mais distante contém vidro e toma mais cuidado. Quando o gari que reduz vê necessidade, entra na residência ou em algum estabelecimento comercial e mostra a forma segura de acondicionar vidros quebrados ou outros objetos perigosos. Dessa forma, pode-se notar pela fala dos garis como é mais seguro coletar o lixo domiciliar usando a estratégia de "redução":
É até estranho um gari chegar dizendo: "Nó...machuquei reduzindo". Aí os cara vai falar assim: "É lero lero". Ninguém nem acredita.

É estranho porque é incomum machucar reduzindo. O lixo tá parado ali. Cê tá vendo ele. Sabe... cê vê ele. Não, correndo não, cê juntou daqui, juntou dali, pá... Aí corta mesmo... suponhamos, o caminhão tá em movimento, cê vai pegar o saco e o caco tão tudo ali na alça, aí você pega. Em movimento eu não vou parar, olhar a sacola, não dá tempo...

... é pelo ver e pelo ouvir, né? Quando cê tá reduzindo você tem um contato maior com o lixo. Você pega o lixo aqui e leva lá pra frente, aí você ouve. Quando você joga lá aí você ouve, pá... tem uma latinha lá dentro, tem vidro, aí separa tudo.

Como já descrito, o monte de lixo da "redução" geralmente é feito do lado direito da rua, porém, mesmo quando feita do lado esquerdo, o motorista encosta o caminhão bem próximo ao monte reduzido e, então, o gari não precisa atravessar a rua para coletar.

O caminhão tá na direita, né? Você corre em cima do passeio, né? Quem tá na esquerda não, tá na contramão. Os carros vão tá vindo. Ele vai ter que atravessar, olhar, pegar o lixo, olhar o caminhão atravessar. Às vezes nessas troca de ação aí ele tá sujeito a ser atropelado...

Os garis relatam que a carga mental é menor com a "redução". Sem "redução" precisam ficar o tempo todo concentrados, já que é preciso ter muita atenção, principalmente nos locais com trânsito mais intenso de carros e pessoas.

Além disso, o conflito com os motoristas diminui quando a "redução" acontece, pois o motorista do caminhão necessitará permanecer em cada local por um tempo mínimo, já que os montes estão praticamente pré-determinados e o gari permanece apenas na mão da via.

Desgaste mental? Há... Buzinação, xingação. Tá ligado! Você tê que ficá concentrando assim. Isso acontece quando você pára no trânsito, o motorista começa a xingar, buzinar, sabe?... Então de ter um desgaste menor quando tem "redução".

\section{Possibilidade de relações sociais com a comunidade}

As interações sociais com a comunidade são aspectos positivos do trabalho ressaltados pelos garis ${ }^{11}$. A "redução" propicia relação mais intensa com a comunidade local, por isso consideram pior a parte inicial da coleta (onde há menos contato com a comunidade), trecho em que não fazem "redução".

Onde num reduz num dá nem tempo de conhecer o pessoal direito. A gente conhece menos.

Quando não faz "redução" cê passa correno, cê vai dá só um tchau. Às vezes cê tá correno, aí um grita:

\footnotetext{
${ }^{11}$ Demonstram, inclusive, sua insatisfação quando são transferidos de rotas de coleta, o que tem sido intensificado pela terceirização dos serviços.
} 
"ô colega". Aí você vê um suco, um lanchinho. Aí cê tá lá na frente e a senhora grita: "um lanche procês”. Aí o caminhão tem que dá uma volta.

Quando me mudaram de trecho... nossa... mudar de trecho é uma tristeza pra nós!

No natal tem presente, quando a gente precisa de alguma coisa é só falar! Hoje a gente ganha muito menos, mas ainda tem tanta cesta de Natal!

Muitas vezes os garis coletam restos de poda, colchões, sofás e outros móveis velhos. Embora sendo lixo que não deveria ser coletado por eles, é colocado no caminhão por vários motivos: "a gente ganha lanche, água, quando precisa usar telefone em caso de acidente... são nossos amigos”.

\section{Regulação da carga de trabalho pelo trabalho co- letivo}

Algumas equipes fazem rodízio diário ou semanal entre as duplas que vão reduzir ou decidem na hora quem vai reduzir naquele dia, dependendo do estado de saúde de cada um. Outras equipes não fazem rodízio entre "redução" e coleta (que chamam de "bateção"), de forma que é sempre a mesma dupla que reduz e a outra que sempre "bate" o lixo reduzido, por exemplo, no caso de um gari que relata sentir muita dor nas pernas ao saltar do estribo e que sempre faz a "redução" criando os montes de lixo.

Desta forma, a estratégia da "redução" também permite uma construção do trabalho coletivo de forma a promover uma regulação coletiva do desgaste provocado pela atividade:

Porque quando você reduz é mais fácil, então igual, por exemplo, eu tô reduzindo e eles tão lá atrás batendo. Porque se nós quatro reduzir junto quando o caminhão chegar do aterro nós tão junto. Mas é até pra evitar o desgaste né? Por exemplo, eu reduzo hoje e os dois ficam. Aí eu vou ter o benefício de reduzir primeiro e vir embora e os dois vai ficar lá batendo.

De quarta a sábado todo mundo beneficia porque alterna sabe... Eu acho que o benefício é o conjunto. Não existe um benefício único não sabe! Mas se separar o benefício é maior pra quem reduz. Eles vêm embora e quem bate fica lá trabaiando. O desgaste não vai tê tanto. A guarnição toda vai beneficiar porque eu vou ter o tempo pra eu ir lá juntar tranqüilo... os outros também vão trabalhar tranqüilo porque eles vão pegar o lixo todo na direita, amontoadinho...

A guarnição toda vai beneficiar. Porque eu vou ter o tempo pra eu ir lá juntá tranqüilo sem o caminhão atrás de mim pra me apressar. Tá ligado! Tranqüilo... assobiando... e os outros vão também trabalhar tranqüilo por quê? Eles vão pegar o lixo todo na direita, amontoadinho, não vai ter o perigo de carro atropelar, de cortar, de machucar sabe? Eu já separei tudo!... aí por isso que eu te digo que o benefício vai ser o conjunto.

Assim, os garis também se dividem para regular o tempo da jornada de trabalho, como no caso do gari que tem um compromisso naquele dia e precisa sair mais cedo. Ele faz a "redução" e termina o trabalho mais cedo. Percebeu-se, ainda, que o trabalho de coleta de lixo domiciliar, quando realizado com a "redução", possibilita ao trabalhador uma liberdade maior de atender às suas necessidades básicas, como uso de sanitários, ingestão de líquidos e alimentos.

\section{Avaliação da carga fisiológica por dados cronotró- picos}

Foram coletados os dados cronotrópicos (freqüência cardíaca/FC e pressão arterial/Pa) comparando os dois tipos de coleta de forma intrapessoal. Tais dados foram coletados durante duas jornadas de trabalho de um mesmo dia da semana: em um dia não foi feita "redução" e no mesmo dia da outra semana os garis trabalharam normalmente.

Para entendimento do texto, é preciso esclarecer que o Gari 1, apesar de não ter feito "redução", coletou o lixo deixado em montes pelo Gari 2, que fez a "redução" num dia. Também é importante esclarecer que ambos fizeram a coleta sem "redução" e que a comparação dos dados foi intrapessoal, ou seja, o Gari 1 foi comparado com ele mesmo coletando os montes da "redução" e coletando de porta em porta. O mesmo foi feito com o Gari 2, fazendo "redução" e coletando de porta em porta. Ressaltamos ser necessário um estudo fisiológico mais aprofundado e específico, apesar de podermos demonstrar as considerações abaixo.

A partir do repouso, as FC (bpm) tiveram momentos de pico, direcionando-se para cima ou para baixo de acordo com a rota que os garis iam fazendo (subida ou descida de morros ou em linha reta). Infere-se, pois, que as peculiaridades do trabalho analisado - intermitente e com oscilação dos montantes de lixo carregados (força empregada) - influem nas condições de gradatividade da FC em função da prestação laboral.

O trabalho realizado com "redução" pode afetar, sensivelmente, a FC dos garis, sendo ainda mais visível no gari que faz a "redução", que, em repouso, teria 85 bpm e, após $15 \mathrm{~min}$ de repouso, teria $89 \mathrm{bpm}$. Isso, associado aos dados qualitativos mencionados anteriormente, reforça que a "redução" beneficia a homeostasia do organismo e a adaptação às alterações decorridas do trabalho pesado.

Todavia, é a partir da análise da Freqüência Cardíaca Submáxima (65\% a 80\% da FCmáx prev) e da FC máxima alcançada (FCmáx alc) com e sem a estratégia de "redução" que se abre espaço a ponderações de interesse crucial ao estudo proposto, quais sejam: a FCsubmax do Gari 1 (não faz "redução") permaneceu entre 140,25 e 149,6 bpm e a do Gari 2 (faz "redução”), entre 138,75 e 148 bpm; a FCmáx alc na "redução" e sem a "redução" do Gari 1 (não faz "redução") foi de 170 bpm; o Gari 2 (faz "redução") alcançou FC sem "redução" de 170 bpm, mas com “redução” obteve 151 bpm. 
Tais dados nos permitem afirmar que o gari que faz a "redução" pode ter como benefício a possibilidade de ficar mais próximo da FCsubmáx, o que equivale, pois, a um treinamento contínuo de resistência aeróbica sem causar danos ao aparelho cardiovascular.

A média do Gari 1 (coleta o monte reduzido) na "redução" foi de 140,48 bpm e, sem a "redução", de 144,61 bpm. Já o Gari 2 (faz "redução") obteve média de 125,01 bpm na "redução" e 144,72 bpm sem a "redução". Mais uma vez, o Gari 2, que criou os montes de lixo, obteve média menor que o outro, mas o Gari 1 também teve o benefício de diminuir a sua média da FC quando trabalhou em equipe com garis que reduziram na segunda viagem da coleta.

De acordo com Grandjean (1998), um trabalho é considerado de carga regular quando a FC se compreende no intervalo de 100 a $125 \mathrm{bpm}$, carga alta quando a FC está entre 125 e 150 bpm, carga muito alta entre 150 e $175 \mathrm{bpm}$ e extremamente alta acima de 175 bpm. Pôde-se perceber, com base na análise das médias e FCs máximas alcançadas na "redução" e sem a "redução", que o trabalho com a "redução" é considerado como carga regular e o trabalho sem a "redução" chega a representar até mesmo carga alta a muito alta.

A PA (mmHg) dos garis investigados, como esperado, ao final retornou aproximadamente ao nível basal, ou seja, nível de repouso.

Ao observarem os dados relativos à carga fisiológica de trabalho, os trabalhadores relacionaram o uso da "redução" à diminuição da necessidade de correr:

Com a redução corre menos.

Não precisa correr, o caminhão encosta, você coleta e pronto. Num tem trânsito, num tem correria.

Não foi possível repetir três vezes as medições para se fazer uma média devido à variabilidade do trabalho dos garis, ou seja, cada dia houve um evento novo: um dia o caminhão quebrou, outro dia um gari faltou e foi substituído por um reserva, depois um dos garis saiu de férias. Isso demonstra a dificuldade metodológica para este tipo de pesquisa e demanda um estudo mais aprofundado e específico, como fizeram Legg e Myles (1981) e Kemper et al. (1990), apesar de, ao estudarem a carga fisiológica e biomecânica no trabalho de coletores de lixo, todos terem identificado diferenças entre o estudo de campo e a pesquisa feita em laboratório.

Diante das limitações relativas ao uso da medida de freqüência cardíaca para avaliação do esforço e das dificuldades apresentadas acima, ressaltamos ser necessário um estudo fisiológico mais aprofundado e específico.

\section{Considerações finais}

Guérin et al. (2001) demonstram, ao discorrer sobre as formas de regulações no trabalho, que, diante da falta de "margem de manobra", os trabalhadores encontram-se em situações de sobrecarga de trabalho. É neste sentido que se percebe, após este estudo, a importância do método de "redução" como estratégia coletiva para manter a carga de trabalho em nível mais aceitável e assegurar a qualidade na prestação do serviço. Este estudo demonstrou que a carga de trabalho é menor quando o gari utiliza a estratégia de "redução"12.

Se não fosse a estratégia de "redução", o gari teria um gasto energético maior e, provavelmente, maior incidência de lesões osteomusculares, cortes e atropelamentos. Quando um morador chama o gari para coletar seu lixo após a passagem do caminhão, se, na volta, o gari não cortasse caminho fazendo "redução", ele teria que acelerar o ritmo de sua corrida para alcançar o caminhão ou encontrá-lo mais à frente e perderia na produtividade. A "redução" permite até o controle do tempo de coleta, possibilitada pela organização do trabalho coletivo.

Pode-se notar, também, a gestão coletiva feita pelos garis para viabilizar a "redução", confirmando o que pondera Hulbault (2004), para quem todo trabalhador gerencia, sob uma forma necessariamente contingente e mutável, o "problema” colocado continuamente pela exigência de produzir. Ao verificar a resistência dos cidadãos em função do acúmulo de lixo em frente às residências, eles procuram negociar os melhores locais para acumular o lixo, e mais, incorporam-na às regras da "redução", como uma prescrição coletiva do trabalho. As regras da "redução" descritas pelos garis funcionam como trabalho prescrito para todas as equipes de coleta. É método de trabalho gerado pela prática que, no entanto, encontra resistência por parte da organização formal da empresa.

O estudo mostrou ainda que este método de trabalho, quando prescrito pela empresa (a "redução" planejada), causa sobrecarga para os garis, já que é prescrito para momentos em que se deveria utilizar outra forma de coletar o lixo, como no caso da coleta em "becos". Nessa situação, os garis devem caminhar grandes distâncias (até 200 metros) carregando nas mãos todo o lixo até chegarem ao caminhão.

O trabalho mostra a necessidade de estudos detalhados da atividade de trabalho como forma de provar para a empresa que alguns modos operatórios elaborados pelos garis são melhores para sua saúde,

\footnotetext{
${ }^{12}$ Mesmo não tendo sido proposta desta pesquisa, mostrou-se para a empresa que a "redução" também diminui a carga de trabalho para o motorista, diminui o desgaste do caminhão e até o trecho percorrido, de forma que há menos gasto de combustível.
} 
a produtividade, a economia no uso do seu corpo e a diminuição do desgaste promovido pelo trabalho. Os resultados beneficiam a empresa e o trabalhador.

Espera-se que esta pesquisa tenha levantado novos problemas a serem aprofundados. Porém, a expec-

\section{Referências}

ABRAHÃO, J. Ergonomia: modelo, método e técnicas. Apostila de mini-curso. In: II CONGRESSO LATINOAMERICANO E VI SEMINÁRIO BRASILEIRO DE ERGONOMIA. Florianópolis, 1993.

GUÉRIN, F. et al. Compreender o trabalho para transformá-lo. São Paulo: Edgard Blücher, 2001.

GRANDJEAN, E. Manual de ergonomia: adaptando o trabalho do homem. 4. ed. Porto Alegre: Bookman, 1998.

HUBAULT, F. Do que a ergonomia pode fazer a análise? In: DANIELLOU, F. (Coord.). A ergonomia em busca de seus princípios: debates epistemológicos. São Paulo: Edgard Blücher, 2004. p. 105-140.

KEMPER, H. C. G. et al. The physical and physiological workload of refuse collectors. Ergonomics, London, v. 33, n. 12, p. 1471-1486, 1990.

LEGG, S. J.; MYLES, W. S. Maximum acceptable repetitive lifting workloads for an 8-hour work-day using psychophysical and subjective rating methods. Ergonomics, London, v. 24, n. 12, p. 907-916, 1981.

MADRUGA, R. B. Cargas de trabalho encontradas nos coletores de lixo domiciliar - um estudo de caso. 2002. 118 f. Dissertação (Mestrado em Engenharia de Produção) - Universidade Federal de Santa Catarina, Florianópolis, 2002.

McARDLE, W. D.; KATCH, F. I.; KATCH, V. L. Fisiologia do exercício: energia, nutrição e desempenho humano. 4. ed. Rio de Janeiro: Guanabara Koogan, 1998.

PAVELSKI, E. C. Aspectos ergonômicos para evitar lesões microtraumáticas em joelhos de coletores de lixo, na cidade de Curitiba, estado do Paraná. 2004. 127 f. Dissertação (Mestrado em Engenharia de Produção) - Universidade Federal de Santa Catarina, Florianópolis, 2004. tativa maior é que esta pesquisa contribua para melhorar a situação de trabalho dos garis, que precisam de maior margem de manobra para poder gerenciar a variabilidade de seu trabalho para economizar seus corpos e trabalhar de forma mais segura.

ROBAZZI, M. L. C. C. et al. Algumas considerações sobre o trabalho dos coletores de lixo. Rev. bras. Saúde ocup., São Paulo, v. 20, n. 76, p. 34-41, jul./ dez. 1992.

ROBAZZI, M. L. C. C.; BECHELLI, M. H. M. Coletores de lixo: estudo de afastamentos do serviço por problemas de saúde. Rev. bras. Saúde ocup., São Paulo, v. 13, n. 50, p. 68-74, abr./jun., 1985.

ROBERGS, R. A.; ROBERTS, S. O. Princípios fundamentais de fisiologia do exercício: para aptidão, desempenho e saúde. São Paulo: Phorte, 2002.

SANTOS, M. C. O. S. Apropriando-se do trabalho: um estudo sobre a atividade dos garis - coletores de lixo. 2004. 168 f. Dissertação (Mestrado em Psicologia Social) - Faculdade de Filosofia e Ciências Humanas, Universidade Federal de Minas Gerais, Belo Horizonte, 2004.

SILVA, E. P. Condições de saúde ocupacional dos lixeiros de São Paulo. Rev. bras. Saúde ocup., São Paulo, v. 11, n. 42, p. 30-35, abr./jun. 1983.

VASCONCELOS, R. C. A gestão da complexidade do trabalho do coletor de lixo e a economia do corpo. 2004. 250 f. Tese (Doutorado em Engenharia de Produção) - Departamento de Engenharia de Produção, Universidade Federal de São Carlos, São Carlos, 2007.

WILMORE, J. H.; COSTILL, D. L. Fisiologia do esporte e do exercício. 2. ed. Barueri: Manole, 2001.

WISNER, A. Questões epistemológicas em ergonomia e em análise do trabalho. In: DANIELLOU, F. (Coord.). A ergonomia em busca de seus princípios: debates epistemológicos. São Paulo: Edgard Blücher, 2004. 